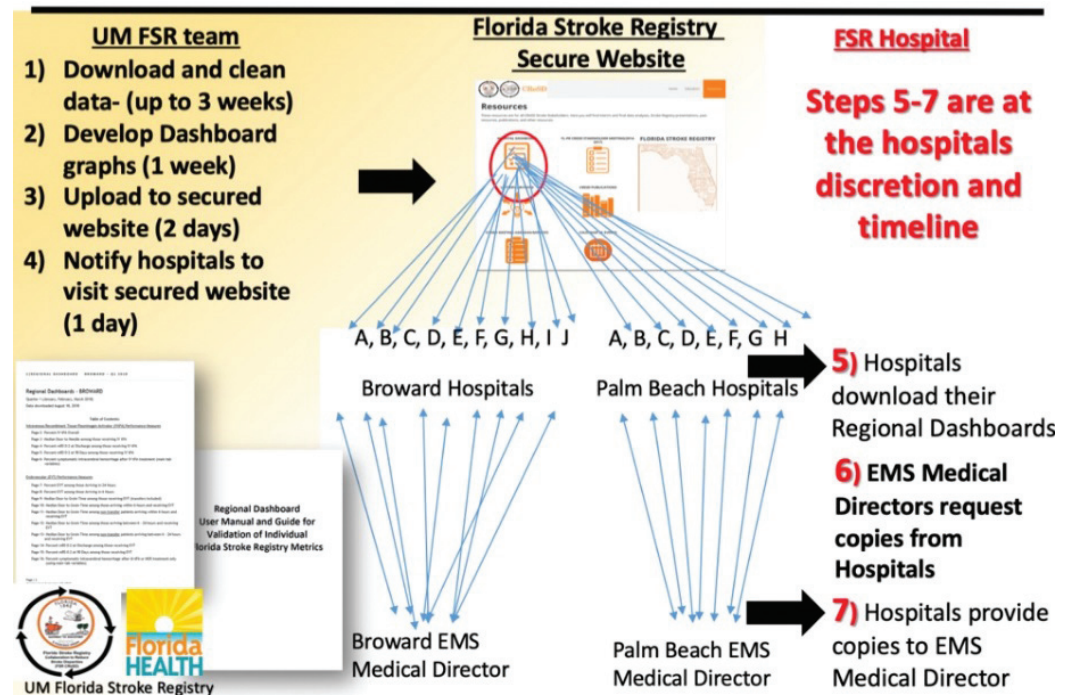

Abstract 3 Figure 1

region that is comprised of a multitude of EMS agencies and numerous ELVO triage destinations within short distance of each other. Taken together, this data transparency initiative will be instrumental for EMS Medical Directors in future triage decision-making.

Disclosures B. Mehta: None. P. Antevy: None. R. Katz: None. J. Sessa: None. K. Scheppke: None. P. Pepe: None. R. Hanel: None. M. Mokin: None. C. Gutierrez: None. J. Romano: None. R. Nogueira: None. A. Jadhav: None. T. Leslie-Mazwi: None. R. Sacco: None.

\section{ATLAS ${ }^{T M}$ STENT ASSISTED ANTERIOR CIRCULATION ANEURYSM COILING: ONE YEAR OUTCOMES}

${ }^{1} O$ Zaidat ${ }^{*},{ }^{2} R$ Hanel, ${ }^{2} E$ Sauvageau, ${ }^{2} A$ Aghaebrahim, ${ }^{1} E$ Lin, ${ }^{3} A$ Jadhav, ${ }^{4} \mathrm{~T}$ Jovin, ${ }^{5} \mathrm{~A}$ Khaldi, ${ }^{5} \mathrm{R}$ Gupta, ${ }^{5} \mathrm{~A}$ Johnson, ${ }^{6} \mathrm{D}$ Frei, ${ }^{6} \mathrm{D}$ Loy, ${ }^{7} \mathrm{~A}$ Malek, ${ }^{8} \mathrm{G}$ Toth, ${ }^{9} \mathrm{~A}$ Siddiqui, ${ }^{10}$ J Reavey-Cantwell, ${ }^{11} \mathrm{~A}$ Thomas, ${ }^{12} \mathrm{~S}$ Hetts, ${ }^{13} \mathrm{~B}$ Jankowitz. ${ }^{1}$ Neuroscience Department, Bon Secours Mercy Health St. Vincent Medical Center, Toledo, OH; ${ }^{2}$ Lyerly Neurosurgery, Jacksonville, FL; ${ }^{3}$ Neurology, UPMC Presbyterian Hospital, Pittsburgh, PA; ${ }^{4}$ Cooper University Hospital Neurological Institute, Camden, Nj; ${ }^{5}$ Neurosurgery, WellStar Kennestone Hospital, Marietta, GA; ${ }^{6}$ Radiology and Medical Imaging, University of Virginia, Charlottesville, VA; ${ }^{7}$ Neurosurgery, Tufts Medical Center, Boston, MA; ${ }^{8}$ Cleveland Clinic Foundation, Cleveland, OH; ${ }^{9}$ SUNY University at Buffalo, Buffalo, NY; ${ }^{10}$ Virginia Commonwealth University Medical Center, Richmond, VA; ${ }^{11}$ Beth Israel Deaconess Medical Center, Boston, MA; ${ }^{12}$ Interventional Neuroradiology, The University of California San Francisco, San Francisco, CA; ${ }^{13}$ Neurological Surgery, UPMC Presbyterian Hospital, Pittsburgh, PA

\subsection{6/neurintsurg-2019-SNIS.227}

Background and purpose Stent-assisted coil embolization using the new generation Neuroform Atlas ${ }^{\mathrm{TM}}$ Stent System has shown promising technical, safety, and clinical feasibility and efficacy. Here, we present the one year angiographic and efficacy results of the anterior circulation cohort in the ATLAS Investigational Device Exemption (IDE) Trial.
Methods ATLAS IDE is a prospective, multicenter, single-arm, open label study of unruptured wide-necked (neck $\geq 4 \mathrm{~mm}$ or dome-to-neck ratio <2) intracranial aneurysms in the anterior circulation treated with the Neuroform Atlas Stent and approved coils. The primary efficacy endpoint was complete aneurysm occlusion (Raymond class I) on 12-month angiography, in the absence of retreatment, or parent artery stenosis $>50 \%$ at the target location. The primary safety endpoint was any major stroke or ipsilateral stroke or neurological death within 12 months. Adjudication of the primary endpoints was performed by an imaging core laboratory and the Clinical Events Committee for ATLAS.

Results A total of 182 patients with unruptured wide-necked anterior circulation aneurysms at 25 US centers were enrolled. The mean age was $60.3 \pm 11.4$ years, $73.1 \% \quad(133 / 182)$ women, and $80.8 \%(147 / 182)$ Caucasian. Mean aneurysm size and dome-to-neck ratio was $6.1 \pm 2.2 \mathrm{~mm}$ and 1.2 \pm 0.3 , respectively. Sixty-four (35.2\%) aneurysms were located in the anterior communicating artery. Mean procedure duration was 110.2 \pm 47.0 minutes. Technical success was achieved in $100 \%$ $(182 / 182)$ of patients. Follow-up imaging data at 12 months was available in $84.1 \%(153 / 182)$ of patients. The primary efficacy endpoint was achieved in $84.7 \%$ [95\%CI: 78.6,90.9] of subjects and the incidence of primary safety endpoint failure was 4.4\% (8/182; 95\%CI: $1.9,8.5)$.

Conclusion In the ATLAS IDE anterior circulation cohort premarket approval study, the Neuroform ATLAS stent with adjunctive coiling demonstrated high rates of long-term complete occlusion at 12 months, with excellent technical success and safety.

Disclosures O. Zaidat: None. R. Hanel: None. E. Sauvageau: None. A. Aghaebrahim: None. E. Lin: None. A. Jadhav: None. T. Jovin: None. A. Khaldi: None. R. Gupta: None. A. Johnson: None. D. Frei: None. D. Loy: None. A. Malek: None. G. Toth: None. A. Siddiqui: None. J. Reavey-Cantwell: None. A. Thomas: None. S. Hetts: None. B. Jankowitz: None. 